\title{
METHODICAL OPTIMISATION OF DRIVETRAINS OF AGRICULTURAL MACHINERY WITH SPECIAL FOCUS ON THEIR ELECTRIFICATION AND ENERGY EFFICIENCY
}

\author{
Roland SCHMETZ, Rhine Waal-University of Applied Sciences, D-47533 Cleves, Germany, roland.schmetz@hsrw.eu
}

If one looks at the development of the engineering sciences in the past decades under the focus of research, one can get the impression that the engineering sciences are developing more and more in the direction of systematic research of existing objects and facts, possible phenomena as well as functional and effect relationships, which often only leads to incremental progress. In other words, in the way that is characteristic for basic research and clearly predominates in the natural sciences. This "scientification" of the engineering sciences seemes to increasingly limit the scope for pursuing disruptive approaches and developing creative solutions in applied and industrial research. In this context, it is precisely the creative genius manifested in its name that distinguishes engineering from the more formal scientific and basic research-oriented natural sciences, especially physics. The aim of this article is therefore to strengthen the creative genius and to show how the optimisation of drivetrains of agricultural machinery can be methodically supported, especially with regard to their increasing electrification and the need to further improve their energy efficiency. In addition, some examples of the successful drivetrain optimisations are given.

Keywords: drivetrain optimisation, agricultural machinery, drivetrain electrification, energy efficiency

\section{INTRODUCTION AND ASPECTS OF DRIVETRAIN OPTIMISATION}

From studying the programmes of relevant engineering conferences and publications concerning the drivetrains of agricultural machines, it is easy to recognise that there is meanwhile a persistently strong trend towards their electrification, thus a so-called megatrend. What such megatrends have in common is that the expectations associated with them initially skyrocket, before a certain disillusionment sets in, which is then followed by a slowly increasing market penetration with solutions that actually bring technical, economic or social progress (Fenn, Raskino, 2008). Analogously, such a megatrend usually triggers many product innovations, of which only the best-suited solutions then later generally prevail. Afterwards, there are only comparatively few product innovations. A similar, but time-delayed pattern also emerges with the onset of prototype production and the subsequent transition to series production for process innovations, whose rate, however, remains significantly higher than the rate of product innovations as a result of the usually continuous process improvements (Abernathy, Utterback, 1978). In this context, the key technology "electric drives" enables both optimisations through modifications to existing solutions and new designs. In both ways, the better the use of the capabilities of electric drives, the better the results will be. Furthermore, experience has shown that both optimisation paths, which are pursued quite early in the product development process, cause very low costs, but significantly determine the properties and cost structures of the solutions developed in this way (VDI, 1990).

The fundamental advantages of electrification of drivetrains are their very good efficiency in converting electrical energy into mechanical energy, the possibility of feeding them with regeneratively (and, if necessary, autonomously) generated energy, and being able to recuperate stored kinetic energy during braking processes. Other advantages are often the (local) absence of emissions and possible extensions of functionality.

Important aspects of a drivetrain electrification are also the updating of the previous specification, the energy efficiency and the type of energy supply from the available energy sources as well as the drivetrain configuration, the related characteristics of electric drives and the realisation of the required transmission range, with special regard to their mutual interaction.

Thus, on the one hand, requirements can often be removed from the specification that are only necessary when using conventional drives or whose inclusion is based on them. On the other hand, additional properties can often be specified that can be realised in the course of electrification of drivetrains with little or no additional effort.

Copyright () 2021 The Authors. Published by Vytautas Magnus University. This is an open-access article distributed under the terms of the Creative Commons Attribution License (CC BY 4.0), which permits unrestricted use, distribution, and reproduction in any medium, provided the original author and source are credited. 
With regard to energy efficiency, there is a need for special consideration or improvement for several reasons. Energy analyses regularly show that the energy costs of highly utilised agricultural machinery have a significant influence on their overall operating costs (Schmetz, 2020). In addition, an unnecessarily high energy demand causes higher emissions of greenhouse gases, nitrogen oxides and other pollutants; be it through the (almost) direct use of fossil fuels, which are ultimately not available in unlimited quantities, or the - in the mix still not fully regenerative for a long time indirect conversion into secondary energy sources such as electricity. In addition, energy-efficient machines can often be built more compact and lighter, generate less noise, vibrations and harshness and run smoother with less wear and machine breakage. And finally, questions of sufficiency and the ostensibly unlimited capacities for regenerative energy production, seen globally, also require more attention. The avoidance of overuse of these capacities was wrongly not really addressed in any of the UN's 17 Sustainable Development Goals for 2030, although according to many indications, such overuse will also have very considerable effects that are contrary to sustainability (UN, 2015).

With regard to drivetrain configuration, there are numerous alternatives for agricultural machinery because of the different types of machines such as all-wheel driven and crawler tractors, trailed vehicles and machines in combinations, self-propelled machines and increasingly also field robots. Therefore, single central or single-axle drives, distributed axle drives, single-wheel or single-chain drives as well as their counterparts with power split and power merging can be wellsuited solutions.

The situation is similar with the available electric motors. But, in practice only permanently excited synchronous or induction motors are used. The otherwise very important advantages of permanent-magnet synchronous motors, however, such as lower mass and smaller construction volume with higher dynamics, have comparatively little relevance for applications in agricultural machinery. Instead, the larger control range with high efficiencies of induction motors, their considerably higher robustness and overload capacity, the lower control effort as well as the higher converter efficiency together with the possibility of multi-motor operation on only one converter are often of greater importance here.

This becomes evident when comparing the resulting possibilities for realising the usual transmission ratio range of agricultural tractors (the rated power should be available as closely as possible in a range of about 2.5 to $40 \mathrm{~km} / \mathrm{h}$ ), which exist in the course of an electrification of their drivetrains (Figure 1). If only a control range from 0 to the nominal speed of the electric motor is provided, a multi-stage (powershift) transmission or a CVT is still required to realise the necessary transmission ratio range. If, in addition, the ranges with nominal power are extended by means of field map control and field weakening to twice the nominal speed possible with synchronous motors or three-and-a-third times the nominal speed possible with induction motors, the number of required gear stages, including a $25 \%$ overlap, can be reduced to six or three gear stages. If, in addition, the required nominal power is imprinted in the characteristics of an electric motor with one-and-a-half times the nominal power, only a two-stage gearbox (or in some cases no gearbox at all) is required in the case of the induction motor. Such an imprint simultaneously causes the most advantageous, farreaching shift of the electric motor characteristic curve into the range with the best efficiency, but requires a converter of larger

size.

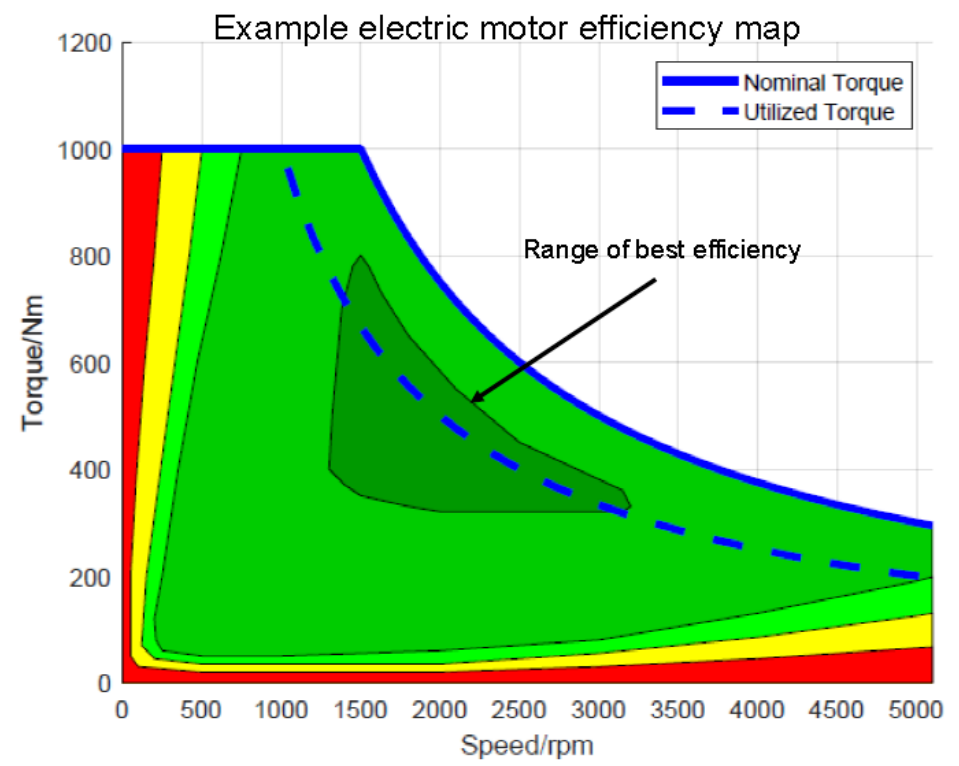

$1^{\text {st }}$ Approach: $\quad 1: 1$ Substitution
Electric motor with speed control range
from $n=0 \ldots$ nominal speed $n_{N}$
$\rightarrow$ Multi-stage gearbox or $C V T^{*}$ required

$2^{\text {nd }}$ Approach: Field map control (FMC)

Extension of the control range by field weakening to $n=0 \ldots 31 / 3 n_{N}$ $\rightarrow$ Three-stage gearbox required $3^{\text {rd }}$ Approach: FMC plus upsizing

\section{Extension of the control range to $\mathrm{n}=0 \ldots 5 \mathrm{n}_{\mathrm{N}}$ (or more) \\ $\rightarrow$ Two-stage (or no) gearbox sufficient}

${ }^{*}$ CVT: Continuously Variable

Transmission

Figure 1. Realisation of Transmission Ratio Ranges by Gears or by Field Weakening?

Only the possibilities for recuperating kinetic energy are not that extensive in agricultural machinery as in some other applications. Despite the often high energy demand of agricultural machines, this is due to their often quite uniform, high utilisation, which is therefore outside or only peripherally in the technically or economically sensible range for energy recuperation due to the lack of pronounced fluctuations. Sometimes this is simply because the amounts of energy that can be recuperated are always doubly reduced by the forward losses in the feed direction and the reverse losses in the return direction for storage (Burghardt, 2013). In addition, hybrid solutions, which are in any case only a now rather 
questionable transitional technology, usually lack sufficient energy storage capacities. For highly utilised agricultural machinery, this also applies to a decreasing extent to fuel cells or batteries as energy sources. However, in view of their often locally limited areas of application, external supplies with a quasi-unlimited storage capacity can also be technically or economically sensible (and possible) for agricultural machinery (Pfaffmann, 2019).

Finally, it can be stated that, from a methodological point of view, optimisations of the drivetrains of agricultural machinery are much more often carried out as (bottom-up) modifications than as (top-down) new designs. However, both forms allow for a variety of solutions that can ultimately only be assessed on a project-specific basis. Therefore, it is obvious to investigate whether there are methodological approaches to guide and support these optimisations.

\section{METHODOLOGICAL APPROACH AND TYPICAL SEARCH AREAS}

Top-down directed new and bottom-up directed change design processes can best be supported by design methodological forward and backward step sequences. For the purpose here, the state of research in this regard is still best represented by the VDI Guideline 2221 of 1993 (VDI, 1993). Of particular importance here are the seven steps of design processes listed therein, which can be gone through forwards, but above all also backwards, and in which the six characterising parameters of functional structure, principle solution, (split in) modules, (shape of) parts, material(s) and manufacturing process are gradually defined or released again for variation (Figure 2). In contrast, the 2019 update of this guideline is less helpful.

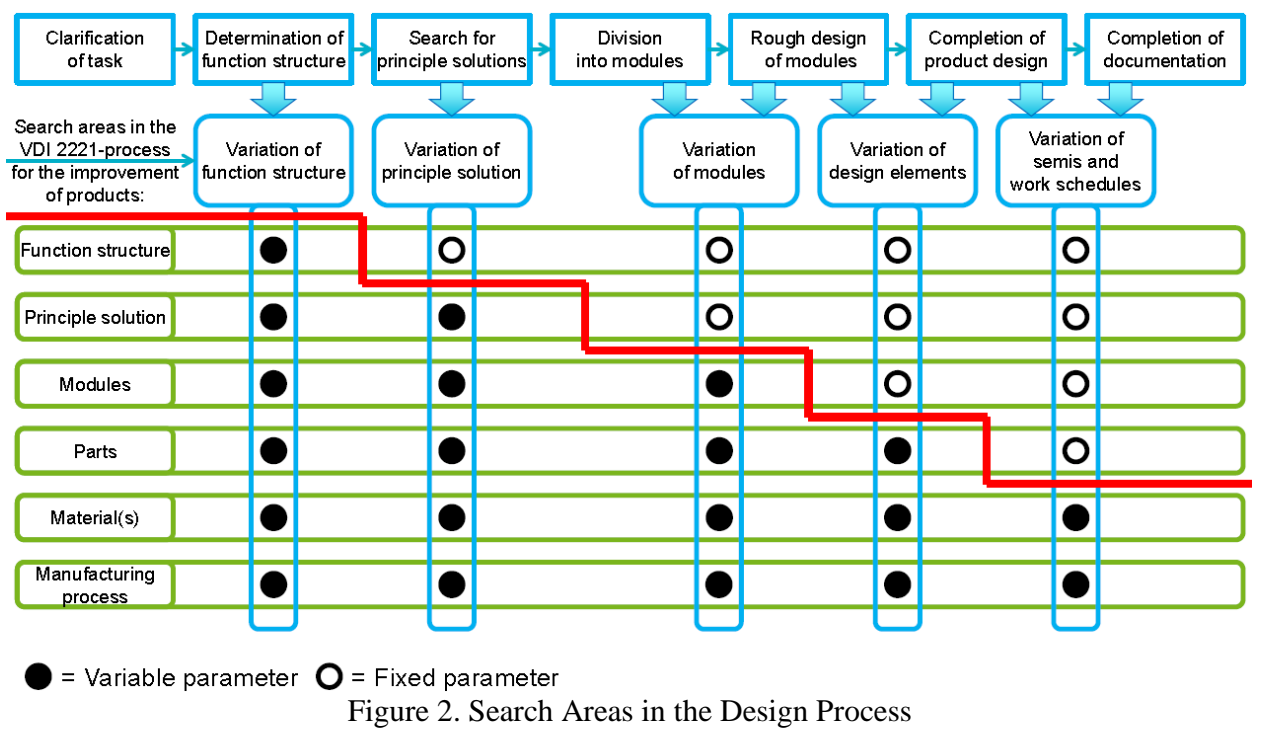

According to Figure 2, for new designs, the functional structure and the principle solution are defined in two corresponding steps at an early stage, while as the staircase shown in Figure 2 continues to descend, the increasing definitions always take place at the transitions from one step to the next. Finally, when the shapes of the parts are already fixed, only (to a limited extent) changes to materials and manufacturing processes (as well as semi-finished products and work process sequences) are possible. Conversely, however, this means that when going up the aforementioned staircase, as happens in the course of (numerically generally much more frequent) change design processes, there are many more degrees of freedom with each step back. For the optimisation of designs in general and for the optimisation of drivetrains in particular, it is therefore very purposeful to look for technical alternatives precisely in the five search fields highlighted in Figure 2.

For this task, various contents of the VDI guidelines 2206, 2222 to 2225 and 4521 (part 3) as well as the VDI guideline families $46 \mathrm{XX}$ and $48 \mathrm{XX}$ can be suitable as aids. In addition, the ongoing documentation of good ideas and essential decisions in earlier and current design processes can also be useful, especially if previously unused ideas or ideas that were not used before but can now be used are recorded in them. Design and other catalogues are often not only helpful indicators for the variation of individual parameters, but can also make it easier to find the respective best practice examples (Pahl, 2007). Particularly helpful for the variation of principle solutions are so-called principle catalogues, which contain a systematic listing of (almost) all suitable physical effects for the realisation of typical basic functions together with application examples, e.g. the catalogues from Koller (1998). In addition, support by methods of artificial intelligence (AI) is possible. A corresponding approach is the collection of if-then rules (currently already comprising about 100 rules) for increasing the energy efficiency of (agricultural and other) machines, which was built up on the basis of knowledge from the following examples, the relevant literature and other sources. This collection can be accessed not only directly, but also with the help of a programme with up to 80 interactive and case-specific pre-screened query masks. The result is then a list with recommendations of measures that are to be checked in particular for their suitability for increasing the energy efficiency of the machine under consideration (Schmetz, 2016).

For a better understanding of the usefulness of the above-described, adequate top-down, but above all bottom-up approaches for the purpose here, a number of relevant examples of successful parameter variations will now be used to 
illustrate. What all these examples have in common is that they enable an increase in energy efficiency and were developed bottom-up in the course of optimising drivetrains.

\section{EXAMPLES OF SUCCESFUL PARAMETER VARIATIONS}

A first, classic case study is the use of hollow instead of full rotor shafts in electric motors. This is because in electric motors the strength of the torque that can be generated increases significantly with the increase in rotor diameter. Therefore, the rotor bars and the active mass of the rotor lamellae or the permanent magnets are arranged as close to the circumference as possible, while only supporting spokes are necessary close to the rotor shaft. In this respect, it is obvious to equip especially larger electric motors with rotor shafts that are hollow (at least) in the area where the rotor lamellae and the other rotor components such as short-circuit rings are attached to the rotor shaft (ThyssenKrupp, 2015). Due to the lower mass inertia, this then results in less kinetic energy having to be stored in the rotor shaft each time the electric motor starts up, which is then often converted into heat loss during braking. Such rotor shafts are usually manufactured from two deep-drawn, cup-shaped shaft halves, which are then joined together by means of friction welding on the hollow sides (Schlatter, 1982). This means that compared to a machining production from a shaft blank, variations have been made with regard to the semi-finished product and the work processes as well as their sequence and also with regard to the shape. In contrast, the essential functional dimensions of the finished rotor shaft with its functional elements have remained unchanged. This case study therefore illustrates an optimisation in which "only" parameter variations have taken place in the last two search fields according to figure 2.

A case study in which the module is also varied, i.e. only the external, functional boundaries of it are retained, is based on an energy analysis of crop conveyance in a self-propelled forage harvester. For this purpose, other influences are eliminated in the relevant calculation step through the best possible settings of travel speed, cutting length, knife clearance and sharpness as well as the assumption of minimal friction through the guidance of crop flow. Without further measures, the crop at rest is then harvested and picked up at approximately walking speed, accelerated in a first step during cutting in the cutting cylinder to a speed of about $40 \mathrm{~m} / \mathrm{s}$ (which is not necessarily required for this purpose alone) before it is accelerated by a blower fan in a second step to a speed of about $70 \mathrm{~m} / \mathrm{s}$ just to be able to blow it sufficiently far into a silage wagon. After unloading, at the latest, the crop is once again at rest. Typical crop flows are often $200 \mathrm{t} / \mathrm{h}$ for silage maize. Typical efficiencies for the blower fan are $70 \%$, for the combustion engine (including all auxiliaries) $35 \%$ and for the belt drive (including clutches) $90 \%$, while the primary energy factor for diesel fuel is 1.35 . This means that the primary energy demand under the above conditions and without further measures is about $3000 \mathrm{MJ}$ or $833 \mathrm{kWh}$ per hour. This rather high primary energy demand can, however, be reduced to a third of its original value by variations of the assembly (with a few tradable functional losses). This can be achieved mechanically by an adjustable engagement of the blower fan in the crop flow by means of its horizontal displaceability (Claas, 2019) or by a crop flow direction by means of an adjustable flap on the inflow side in the blower fan housing (Krone, 2020). Alternatively, the blower fan can also be driven directly by a speed-adjustable electric motor (Batos et al, 2016).

A classic case study for optimisation through a variation of the principle solution is the Eltrac-conversion of the conventional drivetrain of a standard tractor (Schmetz, Kett, 2002). For this purpose, the mechanical shuttle, stepped and range gearboxes located between the tractor engine and the final transmission including rear axle and power take-off gearbox are replaced by a (synchronous) generator and an (induction) motor as well as a stationary shiftable two-stage gearbox. The lever principle previously used in mechanics and realised by gear wheels is now replaced by the electromotive principle. In parallel, the conversion of the generated currents, which are then converted several times electrically and then back into mechanical energy, takes place with the help of electrically controlled power semiconductors, which are located in a specially protected and insulated housing and work according to the principle of resistance change through electrical fields (Schmetz, 2018).

Another case study for a particularly far-reaching optimisation through a function variation is again based on an energy analysis. The object of analysis here is ploughing as a very energy-intensive, but since time immemorial predominant agricultural method for primary soil cultivation, which is used on an equivalent area of almost $100000 \mathrm{~km}^{2}$ per year in the territory of the Federal Republic of Germany alone. According to the state of the art, ploughing not only requires heavy tractors, but also has poor traction efficiency and has so far been little automated. Moreover, the heavy tractors cause increasing soil compaction, while the poor traction efficiency also leads to poor energy efficiency. For example, the net traction power requirement of a six-share plough with a working width of $0.4 \mathrm{~m}$ per furrow at a working depth of $0.3 \mathrm{~m}$, a real working speed of $5 \mathrm{~km} / \mathrm{h}$ and a (soil-, weather- and vegetation-dependent) specific draft resistance of $50 \mathrm{kN} / \mathrm{m}^{2}$ is $50 \mathrm{~kW}$ (Srivastava et al., 2006). With a traction efficiency of 0.6 , the net traction power requirement at the tractor wheels is then already $83.33 \mathrm{~kW}$ (Renius, 2019). Because of the usual efficiencies of $35 \%$ for the tractor engine and $80 \%$ for the tractor drivetrain and the primary energy factor of 1.35 for diesel fuel, the gross traction primary energy demand of $402 \mathrm{~kW}$ is about eight times the net demand.

An analysis of the functional structure quickly shows that the poor energy efficiency has two main causes. One is the poor efficiency of the tractor engine and the other is the poor traction efficiency. An obvious way to remedy the first cause is to substitute the tractor engine with one (or more) electric motor(s). But, this substitution requires additional upstream functions for efficient power supply to the(se) electric motor(s), which have to be additionally synthesised and realised. Without taking into account the problem of increasing soil compaction, the second cause could also be defused by increasing the tractor mass by means of generously dimensioned additional weights. However, a new, far-reaching 
synthesis of the functions for converting mechanical rotational energy into traction energy is also required for a soilprotecting and therefore sustainable remedy.

One possible result of these new syntheses is the Cable Farming-system shown in Figure 3 (compare to Zoffoli, 2012 and Haeussler, 2020). In this system, two multipurpose mobile machines move forward step by step and synchronously on paths along the edges of the field. Such machines are further developed forestry caterpillars, which are equipped with one or more cable winches, devices for additional support of the cable forces (e.g. disc coulters or furrow press rings), remote control and DGPS-based steering systems for precise tracking. The largely automated operation can be controlled and monitored from a central computer that communicates with the on-board computers of the individual machines and implements using a standardised protocol. Each machine (or implement) is an independent one that runs its own operating and navigation system. The orchestration of the farming processes is done by the central computer. The energy supply to the multipurpose machines can be provided (as shown) via cable reels from the field edges. Particularly when systems such as wind turbines or agro- or photovoltaic plants including feed (and possibly also storage) stations are operated near a Cable Farming-system, a close to optimum low-emission and efficient energy supply can be realised. With the Cable Farming-system, not only large shares of the primary, but also of the secondary tillage tasks that arise on many areas of arable land can be carried out with low emissions, energy-efficiently and largely automatically. In addition to the necessary transport, set-up and monitoring activities, the operator only needs to carry out residual work (for example in a conventional manner). For the main work, the shown Cable Farming-system enables several typical operation modes. If pulling ropes are used, then non-driven implements (like the shown plough car) not only for primary, but also for secondary tillage can be pulled over the soil to be worked very precisely and with only low soil pressure. Nevertheless, these implements can also be equipped with on-board functional drive systems as well as DGPS-based position reporting or fine steering systems if required. Alternatively, if equipped with suitable add-ons and if metal ropes are used, the multipurpose machines can stretch local catenaries that are then moved synchronously to the work progress over the arable land to be cultivated. In this way, energy can be supplied with low emissions and efficiently both to powered tillage machines as well as (electrical) tractors if these are still needed. It is also possible to use an (insulated) power cable on one (and a rope from the second) multipurpose machine or to use two (insulated) power cables. In addition, the Cable Farming-system also enables the low-emission and efficient energy supply to a number of other machines, which can be used on the arable land to be cultivated (Schmetz, Hartanto, 2020-1). The use of spider cams for the other equipment for special care of single plants is possible, too.

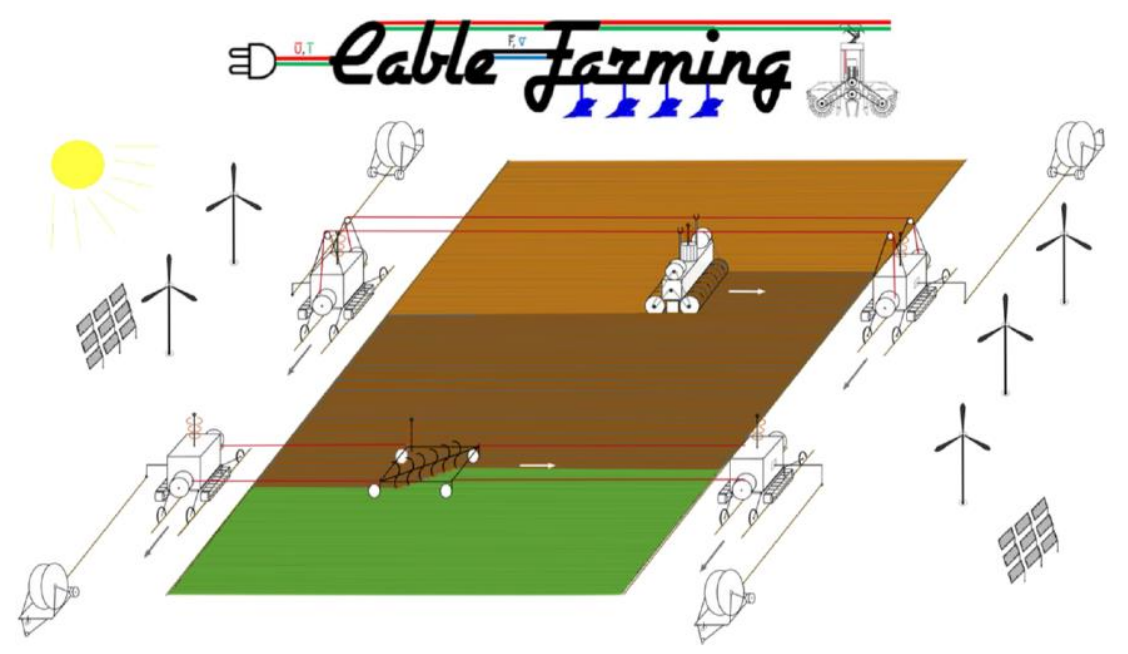

Figure 3: Cable Farming-System (Schmetz, Hartanto, 2020-2)

As the agricultural process "ploughing" is not changed in the Cable Farming-system, the net power requirement for the plough car of this system also remains at around $50 \mathrm{~kW}$. In contrast, however, calculations in this regard lead to increases in traction efficiency and the efficiencies of the mechanical drivetrain and the electric drives to $90 \%$ each, while the primary energy factor for electricity from the German power grid (for the year 2019) is 2.0 and for electricity from exclusively renewable sources 1.1 . This results in gross primary traction power requirements of only $137 \mathrm{~kW}$ and $75 \mathrm{~kW}$, respectively, for an equivalent but significantly more soil-protecting type of primary soil cultivation, compared to the 402 $\mathrm{kW}$ according to the state of the art.

\section{CONCLUSION}

The aim of this article is to motivate the search for significant improvements of drivetrains with special regard to agricultural machinery. Because there is rarely just one way to optimise a drivetrain, but often a variety of options. This is definitely true, if more than simple 1:1 substitutions of existing parts, modules and assemblies are allowed. Particularly in the course of electrification of the drivetrains of agricultural machinery, both significant improvements for existing solutions and novel solutions are possible. The more cleverly and effectively the capabilities of electric drives are exploited, the better the improvements and new solutions that can be achieved. According to the described analysis of 
adequate new, but above all the more frequent change design processes, there are five search fields in which - pursued bottom-up - restrictions previously made under other boundary conditions can be lifted step by step and, if necessary, set differently. When used bottom-up and then top-down again, these five search fields not only serve to guide optimisations in the targeted manner. The search in these five areas can also be supported by aids as parts of known design methods, energy and resource analyses and artificial intelligence systems. With these aids, significant improvement potentials can be tracked down and made usable. For validation, four examples are given. Three of them enable huge increases in energy efficiency. While the savings in the rotor shaft example depend very much on the respective load spectra, the module variation regarding the crop flow when forage harvesting enable savings up to $67 \%$ of the primary (and usable) energy demand for this. By changing the function structure accompanied by providing a direct supply with exclusively renewable energy, the ploughing process hosts a saving potential up to $80 \%$ of its current primary energy demand. This potential is rendering for its utilisation. In the meantime, however, there are not only the four examples of drivetrain optimisations of agricultural machines shown here, but also some other drivetrains of agricultural and other machines have already been optimised with the methodical support described.

\section{REFERENCES}

1. Abernathy W., Utterback J. 1978. Patterns of Industrial Innovation. Technology Review, Vol. 80 No. 7, pp. 40-47.

1. Batos, A. et al. 2016. Possibilities and Limits of an electrically driven Blower Fan installed in a Forage Harvester. Proceedings of the $74^{\text {th }}$ International Conference on Agricultural Engineering, VDI-report Vol. 2273, pp. 325-332.

2. Burghardt M. 2013. Energy recovery - tempting, but not always worthwhile. Polydrive, Vol. 45 No. 2, pp. 29-31.

3. Claas of America Inc. 2019. Forest Harvester (Type 498) Jaguar 900 Series, Omaha

4. Fenn J., Raskino M. 2008. Mastering the Hype Cycle: How to Choose the Right Innovation at the Right Time, Havard Business Press, Boston

5. Haeussler T. 2020. The Bavarian Steam Plough Cooperative Regensburg e.G.m.b.H., $1^{\text {st }}$ ed., Friends of the German Agricultural Museum, Stuttgart

6. Koller R. 1998. Design Methodology for Mechanical Engineering, 4th ed., Springer, Berlin.

7. Maschinenfabrik Bernard Krone GmbH \& Co. KG. 2020. Krone Big X 480, 530, 580, 630 Forage Harvesters, Spelle.

8. Pahl, G., Beitz W., Feldhusen J., Grote K.-H. 2007. Engineering Design: A Systematic Approach, $3^{\text {rd }}$ ed., Springer, London

9. Pfaffmann S., de Moraes Boos F., Tarasinski N., Kegel V. 2019. Swarm Unit - Development of a Fully Electric Agricultural Machine with External Power Supply. Proceedings of the $77^{\text {th }}$ International Conference on Agricultural Engineering, VDI-report Vol. 2361, pp. 401-407.

10. Renius K. 2019. Fundamentals of Tractor Design, $1^{\text {st }}$ ed., Springer, Switzerland. https://doi.org/10.51202/9783181023617-401

11. Schlatter W. 1982. Method of manufacturing a rotationally symmetrical hollow shaft. European Patent No. EP 0052077. https://doi.org/10.1007/978-3-030-32804-7_1

12. Schmetz R. 2016. Search areas for increasing the energy efficiency of mobile machinery - Energetic and ecological product life cycle assessments as drivers for parameter variations in systematic (change) design processes. Proceedings of the $74^{\text {th }}$ International Conference on Agricultural Engineering, VDI-report Vol. 2273, pp. 127-132.

13. Schmetz R. 2018. Calculation of the losses of series-hybrid powertrains. Journal of Agricultural Science and Technology Vol. 8 No. 2, pp. 112-119

14. Schmetz R. 2020. Energy analyses of different advanced drive systems for agricultural machinery. Proceedings of the $78^{\text {th }}$ International Conference on Agricultural Engineering, VDI-report Vol. 2374, pp. 315-322. https://doi.org/10.17265/2161$\underline{6256 / 2018.02 .007}$

15. Schmetz R., Hartanto R. 2020-1. Soil protection and energy savings through efficient energy supply to machines for primary and secondary soil tillage. Proceedings of the $78^{\text {th }}$ International Conference on Agricultural Engineering, VDI-report Vol. 2374, pp. 83-91. https://doi.org/10.51202/9783181023747-315

16. Schmetz R., Hartanto R., 2020-2. Figure Cable Farming-System (Version with Cable Reels). Was shown online during the $78^{\text {th }}$ International Conference on Agricultural Engineering, but hasn't been published yet. Department of Technology. Rhine-Waal University of Applied Sciences, Cleves https://doi.org/10.51202/9783181023747-83

17. Schmetz R., Kett, J. 2002. Eltrac: The tractor with the transmission of the future. Available at https://www.eltrac.de (accessed on 09/10/2021)

18. Srivastava A., Goering C. E., Rohrbach R. P., Buckmaster D. R., 2006. Engineering Principles of Agricultural Machines, $2^{\text {nd }}$ ed., ASABE, St. Joseph.

19. ThyssenKrupp. 2015. Electric Mobility. Available at https://www.thyssenkrupp-automotive-technology.com/en/products-andservices/camshafts-and-e-engine-components/electric-mobility (accessed on 09/10/2021)

20. UN (United Nations). 2015. The 17 Goals. Available at https://sdgs.un.org/goals (accessed on 09/10/2021)

21. 2VDI-guideline 2234. 1990. Basic Economical Information for Design Engineers, Beuth, Berlin

22. VDI-guideline 2221. 1993. Systematic Approach to the Development and Design of Technical Systems and Products, Beuth, Berlin

23. Zoffoli A. 2012. Agricultural furnicular traction system with electric propulsion. European Patent No. EP 2464207 